\title{
Total antioxidant and ascorbic acid content of fresh fruits and vegetables: implications for dietary planning and food preservation
}

\author{
Yim Tong Szeto ${ }^{1}$, Brian Tomlinson ${ }^{2}$ and Iris F. F. Benzie ${ }^{1 *}$ \\ ${ }^{1}$ Department of Nursing and Health Sciences, The Hong Kong Polytechnic University, Kowloon, Hong Kong SAR, China \\ ${ }^{2}$ Division of Clinical Pharmacology, The Chinese University of Hong Kong SAR, China
}

(Received 15 March 2001 - Revised 30 August 2001 - Accepted 11 September 2001)

\begin{abstract}
Epidemiological evidence links high intake of ascorbic acid (AA) and other antioxidant micronutrients to health promotion. It would be useful to know the overall, or 'total' antioxidant capacity of foods, to establish the contribution of AA to this, and to assess how this information may translate into dietary intakes to meet the new US daily reference intake for AA. In this study, the total antioxidant capacity, as the ferric reducing-antioxidant power (FRAP) value, and AA content of thirty-four types of fruits and vegetables were measured using a modified version of the FRAP assay, known as FRASC. This measures AA (reduced form only) simultaneously with the FRAP value. Results covered a wide range: $880-15940 \mu \mathrm{mol} / \mathrm{kg}$ fresh wet weight and $<20-540 \mathrm{mg} / \mathrm{kg}$ fresh wet weight respectively, for FRAP and AA, which comprised $<1-73 \%$ and $<1-59 \%$ total antioxidant capacity of fruits and vegetables respectively. We estimate that $100 \mathrm{mg}$ AA is contained in one orange, a few strawberries, one kiwi fruit, 1-2 slices of pineapple, several florets of raw cauliflower or a handful of uncooked spinach leaves. Apples, bananas, pears and plums, the most commonly consumed fruits in the UK, contain very little AA. Results indicate also that the antioxidant capacity of vegetables decreases rapidly and significantly after fragmentation. Results of this, and future studies, using FRASC as a biomonitoring tool will be useful in food production, preparation, preservation, and aid dietary choices to increase antioxidant and AA intake. Furthermore, FRASC will facilitate bioavailability studies of antioxidants from different foods of known antioxidant capacity and AA content.
\end{abstract}

Antioxidant: Ascorbic acid: Fruit: Vegetable: Bioavailability: Food composition

Diets rich in fresh fruits and vegetables are protective against chronic, degenerative disease (Joshipura et al. 1999; Lampe, 1999; Cox et al. 2000). The beneficial effects of fruits and vegetables are hypothesised to be owing, at least in part, to antioxidants (Halliwell et al. 1995; Collins, 1999; Strain \& Benzie, 1999). Ascorbic acid (AA) is a watersoluble antioxidant known to be important to health (Benzie, 1999; Davey et al. 2000). This has been recognised in the recent increase in the US daily reference intake of AA to 75 and $90 \mathrm{mg} / \mathrm{d}$ respectively, for women and men, with an additional $35 \mathrm{mg} / \mathrm{d}$ recommended for smokers (Larkin, 2000). Plant-based food items contain a wealth of phytochemicals, however, and many have antioxidant properties (Halliwell et al. 1995; Hollman \& Katan, 1997; Strain \& Benzie, 1999; Duthie et al. 2000). In food analysis, individual phytochemicals can be identified and measured, and the comprehensive characterisation of the antioxidant profile of fruits and vegetables is important. However, it would be useful to know the overall, or 'total' antioxidant power (Benzie \& Strain, 1996) of foods, to establish the contribution of AA to this, and to assess how this information may translate into dietary intakes to meet the new US daily reference intake for vitamin C. In the present study, the total antioxidant capacity, as the ferric reducingantioxidant power (FRAP) value, and the AA content of a range of fresh fruits and vegetables were measured. We used a sensitive biomonitoring tool referred to as FRASC (ferric reducing-antioxidant power and ascorbic acid; Benzie \& Strain, 1997). This is a modified version of the FRAP assay (Benzie \& Strain, 1996; US patented) which measures AA simultaneously with the FRAP value. The FRAP value and the relative and absolute contributions of AA to the total antioxidant capacity of the fruits and vegetables tested are presented.

\footnotetext{
Abbreviations: AA, ascorbic acid; FRAP, ferric reducing-antioxidant power; FRASC, ferric reducing-antioxidant power and ascorbic acid.

* Corresponding author: Dr Iris F. F. Benzie, fax +852 2364 9663, email hsbenzie@ polyu.edu.hk
} 


\section{Materials and methods}

Extracts of washed, uncooked, fresh fruits and vegetables were prepared by homogenising $5 \mathrm{~g}$ (fresh wet weight of the edible part, with or without skin and seeds, as would normally be eaten) in $100 \mathrm{ml}$ distilled water for $30 \mathrm{~s}$. Homogenates were filtered, and the total antioxidant capacity and AA (reduced form only) concentrations were measured in triplicate immediately afterwards using an assay known as FRASC (Benzie \& Strain, 1997). Water extracts of vegetables had a near neutral $\mathrm{pH}$, therefore extracts in acetate buffer ( $\mathrm{pH}$ 3.6) were also made, as AA is unstable at neutral $\mathrm{pH}$. We compared FRAP and AA values of neutral $\mathrm{pH}$ and acid extracts to determine if there was a significant, rapid loss of antioxidants in uncooked vegetables following cellular disruption. Extracts of fruits were acidic, and only water extracts of these were made. Seventeen varieties of fruits and seventeen different types of vegetables were tested. For each fruit and vegetable at least three samples, purchased from local shops, were tested, each in triplicate. Results presented are the total antioxidant content as the FRAP value (as $\mu \mathrm{mol} / \mathrm{kg}$ wet weight), the AA content (as $\mu \mathrm{mol} / \mathrm{kg}$ wet weight, and as $\mathrm{mg} / \mathrm{kg}$ wet weight), and the \% total antioxidant capacity of the extract contributed by AA.

The FRASC assay was performed as described in detail elsewhere (Benzie \& Strain, 1997, 1999). In brief, reductants ('antioxidants') in the sample reduce a ferrictripyridyltriazine complex, present in stoichiometric excess, to the blue coloured ferrous form. The change of absorbance at $593 \mathrm{~nm}$ over $4 \mathrm{~min}$ is proportional to the combined (total) FRAP value of the antioxidants in the sample. In the FRASC assay, AA is selectively destroyed by the addition of ascorbate oxidase to one of a pair of sample aliquots. In this case the absorbance change of a sample to which ascorbate oxidase was added is subtracted from the absorbance of a matching aliquot to which water, rather than ascorbate oxidase was added; the difference is due specifically to AA (reduced form only). Change in absorbance $(0-1 \mathrm{~min}$ for AA and $0-4 \mathrm{~min}$ for FRAP) is converted to $\mu \mathrm{mol} / \mathrm{l}$ by comparison with a standard of known AA concentration or FRAP value. Aqueous solutions of ferrous ions (iron(II) sulfate $\left(\mathrm{FeSO}_{4} \cdot 7 \mathrm{H}_{2} \mathrm{O}\right)$ ) and ascorbic acid (L(+)-AA, extra pure crystals) both from Merck (Darmstadt, Germany) are used as calibrators. The FRAP assay has a limit of detection of $2 \mu \mathrm{mol} / \mathrm{l}$, and precision is excellent: within- and between-run CV are $<0.5$ and $1.0 \%$ respectively at between 500 and $2000 \mu \mathrm{mol} / \mathrm{l}$ antioxidantreducing power, $n>8$ in each case. For AA, within- and between-run CV of FRASC are $<5 \%$ at 25, 50, 100, and $440 \mu \mathrm{mol} / \mathrm{l}$.

All reagents and solutions were prepared in Milli-Q water, which was made from a Millipore ultrapure water system (Millipore Corp., Bedford, MA, USA). FRASC reagents were as follows: $300 \mathrm{mmol} / \mathrm{l}$ acetate buffer, $\mathrm{pH} 3 \cdot 6$, prepared by dissolving $3.1 \mathrm{~g}$ sodium acetate trihydrate in distilled water, with $16 \mathrm{ml}$ glacial acetic acid (BDH Laboratory Supplies, Poole, UK) added and made up to 1 litre with distilled water; $10 \mathrm{~mm}-2,4,6$ tripyridyl-S-triazine (Fluka Chemicals, Buchs, Switzerland) solution in $40 \mathrm{~mm}-\mathrm{HCl}$ (BDH Laboratory Supplies); $20 \mathrm{~mm}-\mathrm{FeCl}_{3} \cdot 6-$
$\mathrm{H}_{2} \mathrm{O}$ (BDH Laboratory Supplies) solution in distilled water. Working FRASC reagent was prepared as needed by mixing $10 \mathrm{ml}$ acetate buffer with $1 \mathrm{ml} 2,4,6$ tripyridyl-S-triazine solution and $1 \mathrm{ml} \mathrm{FeCl} 3 \cdot 6 \mathrm{H}_{2} \mathrm{O}$ solution. A $4 \mathrm{IU}$ ascorbic oxidase/ml solution (Sigma Chemical Co., St, Louis, MO, USA) was prepared in distilled water, divided into portions and stored at $-70^{\circ} \mathrm{C}$ until needed.

For FRASC analysis, $100 \mu \mathrm{l}$ of each freshly prepared food extract was mixed with $40 \mu \mathrm{l}$ ascorbic oxidase solution; a matching (paired) $100 \mu \mathrm{l}$ aliquot of each extract was mixed with $40 \mu \mathrm{l}$ water; paired extracts were immediately loaded on the analyser (Cobas Fara centrifugal analyser; Roche Diagnostics Ltd, Basel, Switzerland). The 0-1 min change in $\mathrm{A}_{593} \mathrm{~nm}$ readings of the paired extracts (tested in parallel) were retrieved and used to calculate the AA concentration. The 0-4 min changes in $\mathrm{A}_{593} \mathrm{~nm}$ of the extracts treated with water only (no ascorbic oxidase) were retrieved and used to calculate the FRAP values. The FRAP value in $\mu \mathrm{mol} / \mathrm{l}$ was calculated by simple comparison of $0-4$ min change in absorbance at $593 \mathrm{~nm}$ of the test sample and that of a $\mathrm{Fe}^{2+}$ calibrator, as follows:

$$
\begin{gathered}
\frac{0-4 \mathrm{~min} \Delta \mathrm{A}_{593 \mathrm{~nm}} \text { of test sample }}{0-4 \mathrm{~min} \Delta \mathrm{A}_{593 \mathrm{~nm}} \text { of standard }} \\
\times\left[\mathrm{Fe}^{2+}\right] \text { standard }(\mu \mathrm{mol} / \mathrm{l}) .
\end{gathered}
$$

The AA value in $\mu \mathrm{mol} / \mathrm{l}$ was calculated by comparison of $0-1$ min change in absorbance at $593 \mathrm{~nm}$ of the extract and that of an AA calibrator, as follows:

$$
\begin{aligned}
0-1 \min \Delta \mathrm{A}_{593 \mathrm{~nm}}= & \left(0-1 \min \Delta \mathrm{A}_{593 \mathrm{~nm}} \text { sample }- \text { ao }\right) \\
& -\left(0-1 \mathrm{~min} \Delta \mathrm{A}_{593 \mathrm{~nm}} \text { sample }+ \text { ao }\right),
\end{aligned}
$$

and

$$
\begin{aligned}
& \text { AA concentration }(\mu \mathrm{mol} / \mathrm{l}) \\
& \begin{aligned}
= & \frac{0-1 \min \Delta \mathrm{A}_{593 \mathrm{~nm}} \text { of test sample }}{0-1 \min \Delta \mathrm{A}_{593 \mathrm{~nm}} \text { of standard }} \\
& \times[\mathrm{AA}] \text { standard }(\mu \mathrm{mol} / \mathrm{l}),
\end{aligned}
\end{aligned}
$$

where ao is ascorbic oxidase.

AA was converted from $\mu \mathrm{mol} / \mathrm{l}$ extract to $\mathrm{mg} / \mathrm{kg}$ wet weight of fruit or vegetable by simple calculation based on molecular mass of AA (176), the weight of fruit or vegetable extracted and the volume of fluid used for extraction (typically $5 \mathrm{~g}$ and $100 \mathrm{ml}$ respectively). The $\%$ contribution of AA (which has a stoichiometric value of 2 in the FRAP assay, i.e. $1 \mathrm{~mol} \mathrm{AA}$ reduces $2 \mathrm{~mol} \mathrm{Fe} e^{3+}$ to $\mathrm{Fe}^{2+}$ ) to the total antioxidant capacity (FRAP value) of each fruit or vegetable tested was calculated as follows:

$$
\frac{\mathrm{AA}(\mu \mathrm{mol} / \mathrm{l}) \times 2}{\text { FRAP value }(\mu \mathrm{mol} / \mathrm{l})} \times 100 \% \text {. }
$$

\section{Results}

Results for FRAP and AA showed a wide range (Tables 1 and 2). AA comprised $<1-73 \%$ total antioxidant content of fruits, and $<1-59 \%$ for vegetables. Strawberries were 
Table 1. Total antioxidant power ${ }^{*}$ and ascorbic acid content of aqueous extracts of fruits $\dagger$ (Mean values and standard deviations for triplicate determinations on three or more fruits)

\begin{tabular}{|c|c|c|c|c|c|c|c|}
\hline \multirow[b]{2}{*}{ Fruit } & \multicolumn{2}{|c|}{$\begin{array}{c}\text { FRAP } \\
(\mu \mathrm{mol} / \mathrm{kg} \text { fresh } \\
\text { wet wt) }\end{array}$} & \multicolumn{2}{|c|}{$\begin{array}{l}\text { Ascorbic acid } \\
\text { (mg/kg fresh } \\
\text { wet wt) }\end{array}$} & \multirow{2}{*}{$\begin{array}{c}\text { 'Total' vitamin C } \\
\text { (ascorbic acid plus } \\
\text { dehydroascorbic acid) } \\
\text { (mg/kg fresh wet wt) } \ddagger\end{array}$} & \multirow{2}{*}{$\begin{array}{l}\text { Contribution } \\
\text { (\%) of ascorbic } \\
\text { acid to total } \\
\text { antioxidant power§ }\end{array}$} & \multirow{2}{*}{$\begin{array}{c}\text { Tested with } \\
(+) \text { or without } \\
(-) \text { skin and/or seec }\end{array}$} \\
\hline & Mean & SD & Mean & $S D$ & & & \\
\hline Strawberry & 15940 & 2780 & 540 & 60 & 770 & 39 & $+/+$ \\
\hline Lemon & 10400 & 1480 & 420 & 70 & 580 & 46 & $-1-$ \\
\hline Plum & 9280 & 2240 & 10 & 10 & 40 & $<1$ & $+1-$ \\
\hline Orange & 9420 & 2740 & 330 & 40 & 540 & 40 & $-1-$ \\
\hline Kiwi fruit & 8200 & 220 & 520 & 100 & 590 & 73 & $-1+$ \\
\hline Grapefruit & 8080 & 300 & 390 & 10 & 360 & 54 & $-1-$ \\
\hline Persimmon & 7740 & 5020 & 80 & 60 & & 11 & $+1-$ \\
\hline Apple (green) & 6300 & 160 & $<50$ & & 60 & $<1$ & $+1-$ \\
\hline Apple (red) & 4200 & 420 & $<10$ & & & $<1$ & $+1-$ \\
\hline Mandarin & 5400 & 760 & 240 & 20 & $200^{\|}$ & 50 & $-1-$ \\
\hline Mango & 5060 & 140 & 210 & 40 & 370 & 48 & $-1-$ \\
\hline Grape (green) & 4780 & 2300 & 20 & 10 & 30 & 6 & $+1-$ \\
\hline Grape (red) & 4160 & 980 & $<10$ & & & $<1$ & $+1-$ \\
\hline Banana & 4200 & 320 & $<10$ & & 110 & $<1$ & $-1-$ \\
\hline Pear & 4080 & 1080 & $<10$ & & 60 & $<1$ & $+1-$ \\
\hline Pineapple & 3480 & 1420 & 100 & 20 & 120 & 33 & $-1-$ \\
\hline Chinese pear & 1460 & 440 & $<10$ & & & $<1$ & $+1-$ \\
\hline
\end{tabular}

FRAP, ferric reducing-antioxidant power.

* Expressed as the FRAP value.

†For details of samples and procedures, see p. 56.

$\ddagger$ Values taken from McCance and Widdowson's The Composition of Foods (Holland et al. 1991).

$\S$ The stoichiometric factor of ascorbic acid in the FRAP assay is $2 \cdot 0$; hence, $1 \mu \mathrm{mol}$ ascorbic acid is equivalent to $2 \mu \mathrm{mol}$ antioxidant power (as FRAP)

\|V Value is for canned mandarins.

particularly high in AA and antioxidant capacity. Kiwi fruit contained the highest proportion of AA. Several fruits, however, contained negligible amounts of AA. Of the vegetables tested, choy sum (a Chinese green leafy vegetable similar to kale) had the highest antioxidant capacity. Iceberg lettuce was lowest in antioxidant capacity. There was significant AA in cauliflower, in several Chinese vegetables (choy sum, pak choy, wombok (a cabbage-like Chinese vegetable)), and in spring onion. Results on acidic extracts of some vegetables (cauliflower, cabbage, spring onion and broccoli) were markedly higher than those of water extracts, even though both water- and acetate bufferextracts were made in parallel and measured within a few minutes of fragmentation (Table 2).

\section{Discussion}

Issues of bioavailability mean that caution is needed when interpreting results of in vitro measures, as have been performed here, in an in vivo context. Nonetheless, knowing the AA content of individual foods is useful in planning dietary strategies to meet the new US reference daily intake for AA. In addition, the total antioxidant capacity and the relative contribution to this of AA and non-AA components may be useful indices of the potential health benefits of individual dietary agents. Furthermore, measurement of total antioxidant capacity could be a valuable tool in food technology, as the effect of growing conditions, seasonality, storage, processing, preservation techniques, cooking and genetic modification of plant-based foods could be determined.

The results presented here show that the total antioxidant capacity of fresh fruits and vegetables varies widely, indicating clearly that all servings are not equal in terms of antioxidant intake. Strawberries have an antioxidant capacity up to 10-fold greater than that of other fruits. Plums, oranges, kiwi fruit and grapefruit also have high antioxidant capacity. However, our results show also that plums, while high in other antioxidants, are low in AA. Several other fruits are also low in AA, including apples, pears, grapes and bananas. Evidently, the most commonly consumed fruits in UK are the ones that have the lowest vitamin $\mathrm{C}$ content. Adequate intake, however, could be achieved (in theory) with just one serving of an AA-rich fruit or vegetable. We estimate that about $100 \mathrm{mg}$ vitamin $\mathrm{C}$ is contained within one medium-sized orange, two large strawberries, one kiwi fruit, two slices of pineapple, or one small grapefruit. A few florets of raw cauliflower or a handful of uncooked kale or spinach leaves also contain enough vitamin $\mathrm{C}$ to meet the revised US reference daily intake. However, bioavailability of AA and other antioxidants from different food sources is not completely known, and further work is needed in this area.

Comparing our AA data with published values (taken from McCance and Widdowson's The Composition of Foods (Holland et al. 1991), shown in Tables 1 and 2), it can be seen that the results of our water extracts were lower, and for some vegetables (mange tout and broccoli in particular) markedly so. In Hong Kong these vegetables are invariably imported from overseas, and sub-optimal transport and storage conditions may have resulted in a considerable loss of AA, and perhaps other antioxidants, before purchase of these 'fresh' vegetables. It is unlikely that the method used in this current study (FRASC) underestimated the AA 
Table 2. Total antioxidant power* and ascorbic acid content of vegetables extracted with water and with acetate buffer ( $\mathrm{pH} 3.6) \dagger$ (Mean values and standard deviations for triplicate determinations on three or more vegetables)

\begin{tabular}{|c|c|c|c|c|c|c|c|c|c|c|c|}
\hline \multirow[b]{3}{*}{ Vegetable } & \multicolumn{4}{|c|}{$\begin{array}{c}\text { FRAP } \\
(\mu \mathrm{mol} / \mathrm{kg} \text { fresh wet wt) }\end{array}$} & \multicolumn{4}{|c|}{$\begin{array}{c}\text { Ascorbic acid } \\
\text { (mg/kg fresh wet wt) }\end{array}$} & \multirow{3}{*}{$\begin{array}{c}\text { 'Total' vitamin C } \\
\text { (ascorbic acid plus } \\
\text { dehydroascorbic acid) } \\
\text { (mg/kg fresh wet wt) } \neq\end{array}$} & \multirow{2}{*}{\multicolumn{2}{|c|}{$\begin{array}{l}\text { Contribution } \\
\text { (\%) of ascorbic acid to total } \\
\text { antioxidant power§ }\end{array}$}} \\
\hline & \multicolumn{2}{|c|}{ In water } & \multicolumn{2}{|c|}{$\begin{array}{c}\text { In acetate } \\
\text { buffer }\end{array}$} & \multicolumn{2}{|c|}{ In water } & \multicolumn{2}{|c|}{$\begin{array}{c}\text { In acetate } \\
\text { buffer }\end{array}$} & & & \\
\hline & Mean & SD & Mean & SD & Mean & SD & Mean & SD & & In water & In acetate buffer \\
\hline Choy sum & 10420 & 2820 & 10440 & 2040 & 130 & 60 & 29 & 14 & & 14 & 31 \\
\hline Pak choy & 6200 & 900 & 8440 & 480 & 90 & 20 & 28 & 11 & & 17 & 38 \\
\hline Spring onion & 5900 & 540 & 8040 & 1440 & 150 & 20 & 28 & 5 & 260 & 30 & 39 \\
\hline Wombok & 5620 & 2760 & 6800 & 4200 & 200 & 80 & 28 & 17 & & 40 & 46 \\
\hline Mange-tout & 4900 & 960 & 4460 & 1240 & $<10$ & & 11 & 1 & 540 & $<1$ & 29 \\
\hline Onion & 4320 & 1260 & 2880 & 1300 & 80 & 60 & 5 & 5 & 50 & 22 & 19 \\
\hline Turnip (green) & 3580 & 2160 & 3720 & 2500 & 140 & 110 & 15 & 10 & 170 & 44 & 45 \\
\hline Cabbage (long) & 3500 & 720 & 5000 & 1120 & 110 & 40 & 15 & 6 & 490 & 34 & 34 \\
\hline Broccoli & 2940 & 560 & 7480 & 2460 & 10 & 20 & 10 & 4 & 870 & 4 & 14 \\
\hline Cauliflower & 2840 & 640 & 5880 & 2420 & 140 & 80 & 30 & 23 & 430 & 56 & 59 \\
\hline Garlic & 2680 & 1000 & 2400 & 380 & 60 & 50 & 5 & 2 & 170 & 27 & 22 \\
\hline Tomato & 2360 & 140 & 3120 & 580 & 120 & 60 & 9 & 4 & 170 & 58 & 32 \\
\hline Chinese lettuce & 2300 & 460 & 2280 & 1440 & $<10$ & & 1 & 1 & & $<1$ & 3 \\
\hline Carrot & 1660 & 800 & 2400 & 1500 & 10 & 10 & 1 & 1 & 60 & 5 & 7 \\
\hline Celery & 1560 & 60 & 1340 & 440 & $<10$ & & 3 & 1 & 80 & $<1$ & 27 \\
\hline Potato & 1440 & 320 & 2320 & 960 & $<10$ & & 5 & 2 & 70 & $<1$ & 26 \\
\hline Lettuce (iceberg) & 880 & 260 & 580 & 160 & $<10$ & & $<1$ & & 30 & $<1$ & $<1$ \\
\hline
\end{tabular}

FRAP, ferric reducing-antioxidant power.

${ }^{*}$ Expressed as the FRAP value.

†For details of samples and procedures, see p. 56

$\ddagger$ Values taken from McCance and Widdowson's The Composition of Foods (Holland et al. 1991).

$\S$ The stoichiometric factor of ascorbic acid in the FRAP assay is $2 \cdot 0$; hence, $1 \mu \mathrm{mol}$ ascorbic acid is equivalent to $2 \mu \mathrm{mol}$ antioxidant power (as FRAP).

content per se, as we have shown this method to be specific, accurate and highly reproducible (Benzie \& Strain, 1997, 1999) and AA results obtained by FRASC are very similar to those obtained by a reference HPLC method (WY Chung, YT Szeto and IFF Benzie, unpublished results). In addition, we used freshly prepared extracts, thus minimising postextraction, pre-analytical loss. It should be noted, however, that the previously published AA results (Holland et al. 1991) presented in Tables 1 and 2 represent the sum of the reduced plus oxidised forms of AA, while our results, using FRASC, are for reduced AA only. This methodological difference helps explain at least some of the difference seen. This suggestion is supported by the finding that AA (reduced form) was higher in acidic extracts of most vegetables, indicating that some AA in the water extracts had been oxidised to dehydroascorbic acid before measurement. Nonetheless, some of the difference may be owing to differences in seasonality or variety tested, or related to geographical factors, and this requires further study. We suggest that the simplicity and speed of the FRASC assay makes this a very attractive method for performing studies of this type.

This current study did not investigate the effect of cooking or storage on antioxidant content, but our results indicate that loss of antioxidants from chopped, shredded or pureed vegetables may be rapid and significant. Polyphenol oxidase is found in many plants (Martinez \& Whitaker, 1995; Das et al. 1997), and is responsible for the browning seen in bruised, fragmented or chopped fruit, and for the change, from green to black, which occurs in crushed or chopped tea leaves. The antioxidant capacity of green tea is much higher than that of black tea (Benzie \& Szeto, 1999) because of enzymatic oxidation of polyphenolic tea antioxidants (Weisburger, 1996). A similar loss of phenolic-related antioxidant power in vegetables is likely to occur with crushing, chopping or pureeing. Interestingly, disruption of the vegetable matrix has been reported to increase the bioavailability of folate and lutein, but not of $\beta$-carotene or AA (van het Hof, 1999). Our results suggest that, following cellular disruption, less AA and other antioxidants than expected may remain in the food matrix, and this may affect their apparent bioavailability. A further use of FRASC as a biomonitoring tool, therefore, is in determining the bioavailability of antioxidants in food by monitoring changes in plasma AA concentration and FRAP value after ingestion of food of known (measured) AA and FRAP content.

In conclusion, this current study presents new data, using a novel approach, on the antioxidant capacity and the absolute and relative content of reduced AA in a range of fresh fruits and vegetables, including some Chinese varieties not previously studied. The method used, the FRASC assay, is rapid, reproducible, and relatively simple, making it an attractive biomonitoring tool for nutrition and food technology studies. Results indicate that, in terms of antioxidant capacity and AA, a single serving of some fruits and vegetables is worth several servings of others. Furthermore, results show a rapid loss of antioxidants following fragmentation of some vegetables, and this is prevented by mild acidification. While we do not yet know if increased antioxidant intake is directly beneficial to human health, there is nevertheless a strong inverse 
relationship between dietary antioxidants and all cause mortality, as reported most recently by Khaw et al. (2001). Until the active component(s) of fruits and vegetables are clearly established, measuring their total antioxidant and AA content may be useful in planning diets for health promotion. Furthermore, if it is confirmed that the health benefits of fruits and vegetables are mediated through their antioxidant content, optimising antioxidant intake will become a primary aim in preventive medicine, and determining bioavailability of antioxidants from different food sources will become a priority. Food tables will require updating to include the antioxidant capacity and profile of foods, as well as data on tropical, oriental, and genetically modified varieties not previously studied. FRASC is suitable for this type of work, and will help provide objective data to help plan diets with high antioxidant content and bioavailability. Furthermore, FRASC is useful for studies evaluating methods of food production, preservation, preparation and storage in terms of effects on antioxidant capacity and AA content.

\section{Acknowledgement}

The authors wish to thank The Hong Kong Polytechnic University for funding this work.

\section{References}

Benzie IFF (1999) Prospective functional markers for defining optimal nutritional status: vitamin C. Proceedings of the Nutrition Society 58, 1-8.

Benzie IFF \& Strain JJ (1996) The ferric reducing ability of plasma (FRAP) as a measure of "antioxidant power": The FRAP assay. Analytical Biochemistry 239, 70-76.

Benzie IFF \& Strain JJ (1997) Simultaneous automated measurement of total antioxidant (reducing) capacity and ascorbic acid concentration. Redox Reports 3, 233-238.

Benzie IFF \& Strain JJ (1999) Ferric reducing/antioxidant power assay: direct measure of total antioxidant activity of biological fluids and modified version for simultaneous measurement of total antioxidant power and ascorbic acid concentration. In Methods in Enzymology, vol. 299, pp. 15-27 [L Packer, editor]. Orlando, FL: Academic Press.

Benzie IFF \& Szeto YT (1999) Total antioxidant capacity of teas by the ferric reducing/antioxidant power (FRAP) assay. Journal of Agricultural and Food Chemistry 47, 633-636.

Collins AR (1999) Oxidative damage, antioxidants and cancer. BioEssays 21, 238-256.

Cox BD, Whichelow MJ \& Prevost AT (2000) Seasonal consumption of salad vegetables and fresh fruit in relation to the development of cardiovascular disease and cancer. Public Health Nutrition 3, 19-29.

Das JR, Bhat SG \& Gowda LR (1997) Purification and characterization of a polyphenol oxidase from the Kew cultivar of Indian pineapple fruit. Journal of Agricultural and Food Chemistry 45, 2031-2035.

Davey MW, Van Montagu M, Inze D, Sanmartin M, Kanellis A, Smirnoff N, Benzie IFF, Strain JJ, Favell D \& Fletcher J (2000) Plant L-ascorbic acid: chemistry, function, metabolism, bioavailability and effects of processing. Journal of the Science of Food and Agriculture 89, 825-860.

Duthie GG, Duthie SJ \& Kyle JAM (2000) Plant polyphenols in cancer and heart disease: implications as nutritional antioxidants. Nutrition Research Reviews 13, 79-106.

Halliwell B, Murcia MA, Chirico S \& Aruoma OI (1995) Free radicals and antioxidants in food and in vivo: what they do and how they work. Critical Reviews in Food Science and Nutrition 35, 7-120.

Holland AA, Welch AA, Unwin ID, Buss DH, Paul AA \& Southgate DAT (1991) McCance and Widdowson's The Composition of Foods, 5th ed. London: The Royal Society of Chemistry, Ministry of Agriculture, Fisheries and Food.

Hollman PC \& Katan MB (1997) Absorption, metabolism and health effects of dietary flavonoids in man. Biomedicine and Pharmacotherapy 51, 305-310.

Joshipura K, Ascherio A, Manson AE, Stampfer MJ, Rimm EB, Speizer FE, Hennekens CH, Spiegeleman D \& Willett WC (1999) Fruit and vegetable intake in relation to risk of ischaemic stroke. Journal of the American Medical Association 282, 1233-1239.

Khaw KT, Bingham S, Welch A, Luben R, Wareham N, Oakes S \& Day N (2001) Relation between plasma ascorbic acid and mortality in men and women in EPIC-Norfolk prospective study: a prospective population study. European Prospective Investigation into Cancer and Nutrition. Lancet 357, 657-663.

Lampe JW (1999) Health effects of vegetables and fruit: assessing mechanisms of action in human experimental studies. American Journal of Clinical Nutrition 70, 475S-490S.

Larkin M (2000) Report bodes ill for antioxidant supplementation. Lancet 355, 1433.

Martinez MV \& Whitaker JR (1995) The biochemistry and control of enzymatic browning. Trends in Food Science and Technology 6, $195-200$.

Strain JJ \& Benzie IFF (1999) Diet and antioxidant defence. In The Encyclopedia of Human Nutrition, pp. 95-105 [M Sadler, JJ Strain and B Cabellero, editors]. London: Academic Press.

van het Hof KH, Tijburg LMB, Pietrzik K \& Weststrate JA (1999) Influence of feeding different vegetables on plasma levels of carotenoids, folate and vitamin C. Effect of disruption of the vegetable matrix. British Journal of Nutrition 82, 203-212.

Weisburger JH (1996) Tea antioxidants and health. In Handbook of Antioxidants, pp. 469-486 [E Cadenas and L Packer, editors]. New York, NY: Marcel Dekker Inc. 